\title{
Buying through your teeth: traditional currency and conservation of flying foxes Pteropus spp. in Solomon Islands
}

\author{
Tyrone H. LAVERY and JOHN FASI
}

\begin{abstract}
Globally, island bats are vulnerable to subsistence hunting, with widespread population declines, local extirpations and extinctions. Bats are important to the ecological functioning of remote oceanic islands, and thus the sustainable management of hunting of flying foxes Pteropus spp. is a conservation priority in the Pacific. In Solomon Islands people hunt flying foxes for bushmeat and their canine teeth, which are used as traditional currency. The value of teeth potentially increases hunting pressure on species of Pteropus. We interviewed 197 people on Makira Island to determine the nature of this use and how it may influence flying-fox populations. We asked questions to gather information about hunting practices, the value of canine teeth, utilization of traditional currency, and population trends of Pteropus. Flying-fox teeth remain highly valued on Makira. It is primarily the teeth of $P$. tonganus that are used rather than those of the smaller $P$. cognatus. Although flying foxes are not targeted solely for their teeth, this added value seemingly drives hunters to focus on $P$. tonganus. Hunting varied across five regions of Makira and high hunting pressure corresponded with perceived rarity of $P$. tonganus. Regions with low hunting pressure may be opportune locations to initiate flying-fox conservation on Makira.
\end{abstract}

Keywords Bat, bushmeat, endemic, hunting, island, Melanesia, Pacific, Pteropus

Supplementary material for this article is available at https://doi.org/10.1017/Soo30605317001004

\section{Introduction}

$\mathrm{O}$ ver $60 \%$ of all bat species occur on islands, $24.5 \%$ are island endemics, and $8 \%$ are endemic to single islands (Jones et al., 2009). In the Family Pteropodidae there are 65 species of flying foxes (Genus Pteropus) and 53 of these are

\footnotetext{
Tyrone H. Lavery (Corresponding author) Integrative Research Center, Field Museum of Natural History, Chicago, Illinois, 60605, USA

E-mail tlavery@fieldmuseum.org

JoHN FASI School of Biological Sciences, The University of Queensland, St Lucia, Australia

Received 6 April 2017. Revision requested 31 May 2017.

Accepted 8 June 2017. First published online 16 October 2017.
}

restricted to paleo-tropical islands (Vincenot et al., 2017). In insular systems bats are often the only mammals present and are keystone species, important for pollination, dispersal of plants, and maintenance of ecosystem functioning (Cox et al., 1992; Cox \& Elmqvist, 2000). They are also a disproportionately threatened group of mammals. Thirty-one species of flying foxes are categorized as Critically Endangered, Endangered or Vulnerable on the IUCN Red List (IUCN, 2017) and 28 of these are island species (Vincenot et al., 2017). Pteropus bats generally have low reproductive rates, are predictable in their habits, are a valuable source of protein, and can be susceptible to overharvesting (Mildenstein et al., 2016). The threat of hunting can be greatly accentuated on islands where habitat is limited, there are high frequencies of natural disasters such as cyclones, and human populations are rapidly increasing (Mickleburgh et al., 2002).

Solomon Islands is part of a global biodiversity hotspot, supporting a diverse mammalian fauna that is largely endemic (Mittermeier et al., 2004; Lavery et al., 2016). The majority of Pteropus species that occur in the archipelago are endemic and the distributions of several species are limited to a single island (Lavery et al., 2016). All species are hunted to varying degrees (T. Lavery, unpubl. data). Over 95\% of people in Solomon Islands rely on subsistence agriculture supplemented with wild-harvested foods from the oceans and forests (Solomon Islands Government, 2009a). The rate of human population increase is also the fastest in the region (c. 2.3\% per annum), placing increasing pressure on natural resources (Solomon Islands Government, 2009a).

In Solomon Islands, cash is commonly used to pay for day-to-day goods and services (e.g. buying food from stores and markets). However, many societies continue to use various forms of traditional currency for more important cultural practices, including payment of bride price and settling compensation claims (Connell, 1977). In Solomon Pijin (the most commonly spoken language and lingua franca of Solomon Islands) such traditional practices are referred to as kastom (RAMSI, 2011). Shell money (shells broken into small disks, drilled, smoothed and threaded onto strings) is the most widespread form (Woodford, 1908). However, fossilized clam shell (Tridacna spp.) and mammal teeth are also used to varying extents (Oremus et al., 2015). Traditional currencies on Makira are shell money, dolphin teeth, and canines of flying foxes and domestic dogs. 
Two species of flying foxes occur on Makira: the Pacific flying fox Pteropus tonganus (categorized as Least Concern on the IUCN Red List; Hamilton \& Helgen, 2008) is a widespread species that occurs from Papua New Guinea through to Samoa in the eastern Pacific (Flannery, 1995; Lavery et al., 2016), and the Makira flying fox $P$. cognatus (categorized as Vulnerable; James et al., 2008) is endemic to Makira and satellite islands. Hunting is a recognized threat for $P$. $\operatorname{cog}$ natus. The value of flying-fox teeth as currency could potentially compound existing hunting pressure. However, there is limited understanding of how this traditional use might influence flying-fox populations. Using questionnaire surveys we aimed to quantify the nature of hunting, customary uses and opinions about the conservation of flying foxes on Makira. We aimed to determine if people hunt solely for teeth and which species are targeted, and to quantify hunting pressures to understand the dynamics of the use of flying foxes.

\section{Study area}

Makira lies at the eastern end of the main Solomon Islands chain (Fig 1), and is c. $3,190 \mathrm{~km}^{2}$ in size, reaching over $1,000 \mathrm{~m}$ in elevation. The island supports a population of $>40,000$ people (Solomon Islands Government, $2009 \mathrm{~b})$. Seventeen species of bats from five families have been recorded on the island (Flannery, 1995; Lavery et al., 2016). On Makira flying-fox canine teeth are incorporated into necklaces (Plate 1) for use as traditional currency.

\section{Methods}

\section{Data collection}

We used a mixed methods approach (Creswell, 2012) to generate information about how and why flying foxes are hunted on Makira. We used both quantitative structured questionnaires and qualitative semi-structured interviews as concurrent data collection and analysis tools (Stange et al., 2006; Johnson et al., 2007). Both methods were accorded equal significance (Greene et al., 1989; Cameron, 2009; Jeanty \& Hibel, 2011). The two species of Pteropus on Makira are easily distinguishable based on their external morphology (size, colour, and presence of a bright yellow mantle in P. tonganus). We provided reference photographs of both species during questionnaires to ensure we were collecting data that referred to the correct species.

During 4 weeks in October 2016 four enumerators surveyed 197 participants using structured questionnaires. All four enumerators were mature males above the age of 40 . We chose a stratified sampling approach, aiming to administer 200 questionnaires in total, evenly distributed between

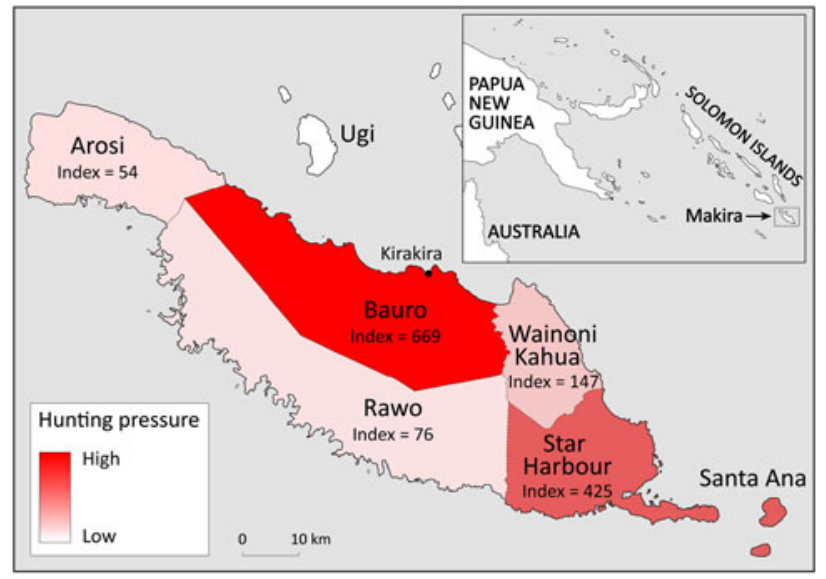

FIG. 1 Makira Island, Solomon Islands, in the south-west Pacific. Indices of hunting pressure on flying foxes, as derived from questionnaire surveys, are indicated for each region. Index $=$ regional population $\times$ mean number of days spent hunting/1,0oo (a higher index indicates greater hunting pressure).

five regions of Makira. We achieved the following samples across the five regions: Bauro (40), Star Harbour/Santa Ana (40), Wainoni/Kahua (40), Rawo (36) and Arosi (41). Within each region we further stratified our sampling by selecting both men and women of various age groups. Eighty-two participants were female and 115 were male.

Our structured questionnaires were divided into three sections to identify (1) gender, age, Christian sect, marital status, and location (i.e. region), (2) views on the current and future uses of traditional currencies, and (3) flying-fox hunting practices, and perceived population trends of $P$. cognatus and $P$. tonganus. For questions relating to the current and future uses of traditional currencies, we used a fourmeasure Likert scale with no midpoint, to ensure that participants made a clear choice rather than opting for a neutral position: 1, Strongly disagree; 2, Disagree; 3, Agree; and 4, Strongly agree (Garland, 1991). An additional seven participants (four male, three female) took part in semi-structured interviews. The 10-minute interview involved five openended questions, facilitating free conversation between the interviewer and interviewee (Jeanty \& Hibel, 2011). Interviews were conducted in Solomon Pijin, recorded with a voice recorder and transcribed verbatim. In Solomon Islands hunting bats is not illegal and thus we had no reason to believe respondents would have withheld information.

\section{Data analysis}

Structured questionnaires were analysed quantitatively. We used log-linear models to test if the proportions of people hunting flying foxes differed by age, gender, location or 


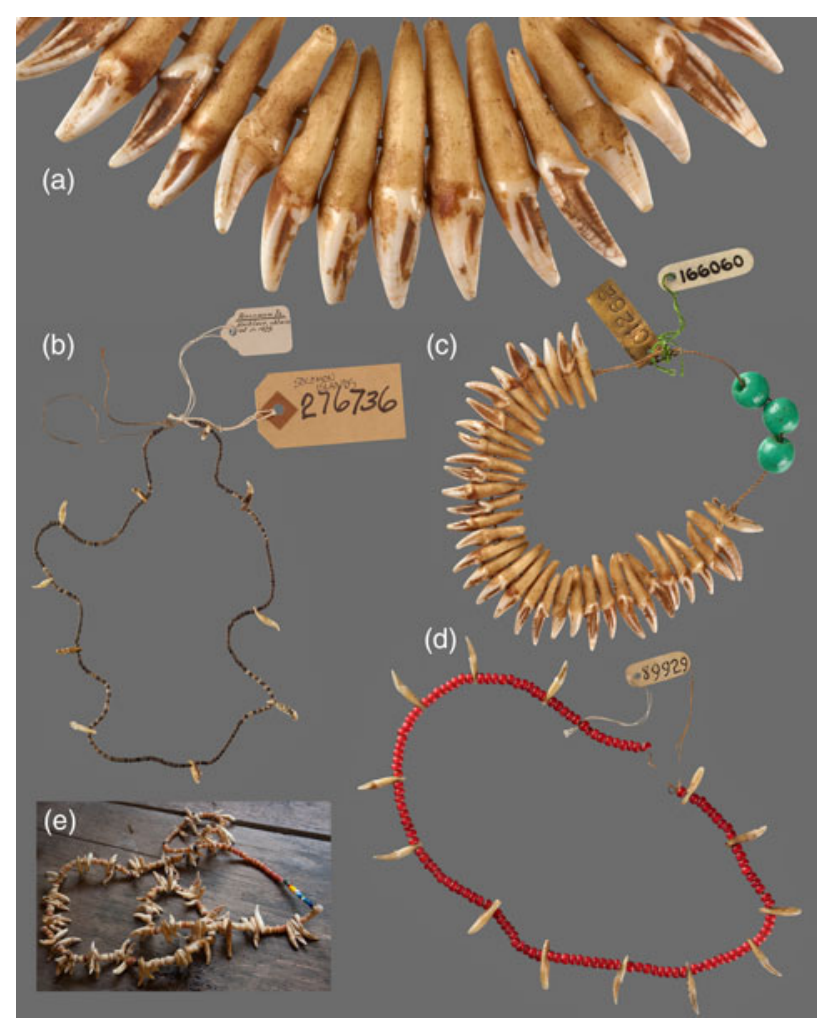

Plate. 1 Solomon Islands traditional currencies and ornaments incorporating Pteropus canines and mammal teeth: (a-d) from the anthropological collections of the Field Museum of Natural History, Chicago; and (e) at Ngora Ngora Village, northern Makira Island (Fig. 1). Images (not to scale) by J. Weinstein (a-d) and T. Lavery (e).

Christian sect. We also tested for interactions between age and gender. All statistics were calculated using the MASS library (Venables \& Ripley, 2002) in $R$ v. 3.3.2 (R Development Core Team, 2016).

We calculated an index of hunting pressure for each of the five regions. We used the proportion of participants from each region who answered yes to the question 'Do you hunt flying foxes?' multiplied by the mean number of days per year people spent hunting flying foxes in that region.

The relative importance of various commodities to culture and society was gauged by asking participants to rank each using the following categories: $2=$ very valuable; $1=$ valuable $-1=$ least valuable; and $-2=$ no value. Using this scale we identified the value of traditional currency, Solomon Islands dollars, pigs, local food (taro, yams, sweet potatoes and bananas), and store-bought food. In a separate question we asked people to use the same ranking for four forms of traditional currency: shell money, flyingfox teeth, dolphin teeth, and dog teeth. Data were summarized using the mean values of responses, such that a value of 2.0 would indicate that all participants thought a commodity was very valuable and a value of -2.0 would indicate that all participants considered a commodity had no value.

We used ordinal regressions (Fernández-Navarro et al., 2015) to test if the age (binned by decade), gender or region of participants influenced their Likert scale responses to three statements: (1) Solomon Islands dollars are replacing traditional currency; (2) Traditional currency is becoming more difficult to find or more expensive; and (3) In the future there will be no need for traditional currency. The dependent variables in each regression were the ranked responses of participants: strongly disagree, disagree, agree, and strongly agree (Boone \& Boone, 2012). The bestperforming models for each test were selected based on Akaike's information criterion values (Akaike, 1973).

All studies involving human participants were compliant with the University of Queensland Institutional Ethical Standards, which conform to provisions contained in the National Statement of Ethical Conduct in Human Research.

\section{Results}

\section{Demographics and geography of hunting}

Males were more likely to hunt flying foxes than females $(\mathrm{F}=3.48, \mathrm{df}=2, \mathrm{P}<0.001)$. There was no overall bias in the age of people who hunted $(\mathrm{F}=3.48, \mathrm{df}=2, \mathrm{P}=0.38)$, and the age of people who hunted did not vary between men and women (there was no interaction between gender and age; $\chi^{2}=3.48, \mathrm{df}=2, \mathrm{P}=0.18$ ) (Fig. 2).

The proportion of people that hunted and the frequency with which they hunted flying foxes varied regionally $(\mathrm{F}=7.31, \mathrm{df}=4, \mathrm{P}=0.03$; Table 1; Fig. 1). Respondents from Bauro hunted most frequently (mean 66.1 \pm SD 103.3 days per year), and from Arosi least frequently (mean 5.6 \pm SD 9.9 days per year). In the four regions with greatest hunting pressure the majority of people believed that both species of Pteropus were in decline (Table 1). Arosi was the only region where a large proportion of the population believed both species of Pteropus were either stable or increasing in number (Table 1).

\section{Hunting and conservation}

A majority of questionnaire participants (78\%) reported that flying foxes were hunted on Makira both for bushmeat and for their teeth. Eleven of these (all from Bauro) indicated that selling flying foxes for money was an additional motive for hunting. Forty-two respondents (21.4\%) reported that flying foxes were hunted only for their meat, and only one stated that hunting was for the sole purpose of collecting canine teeth. 


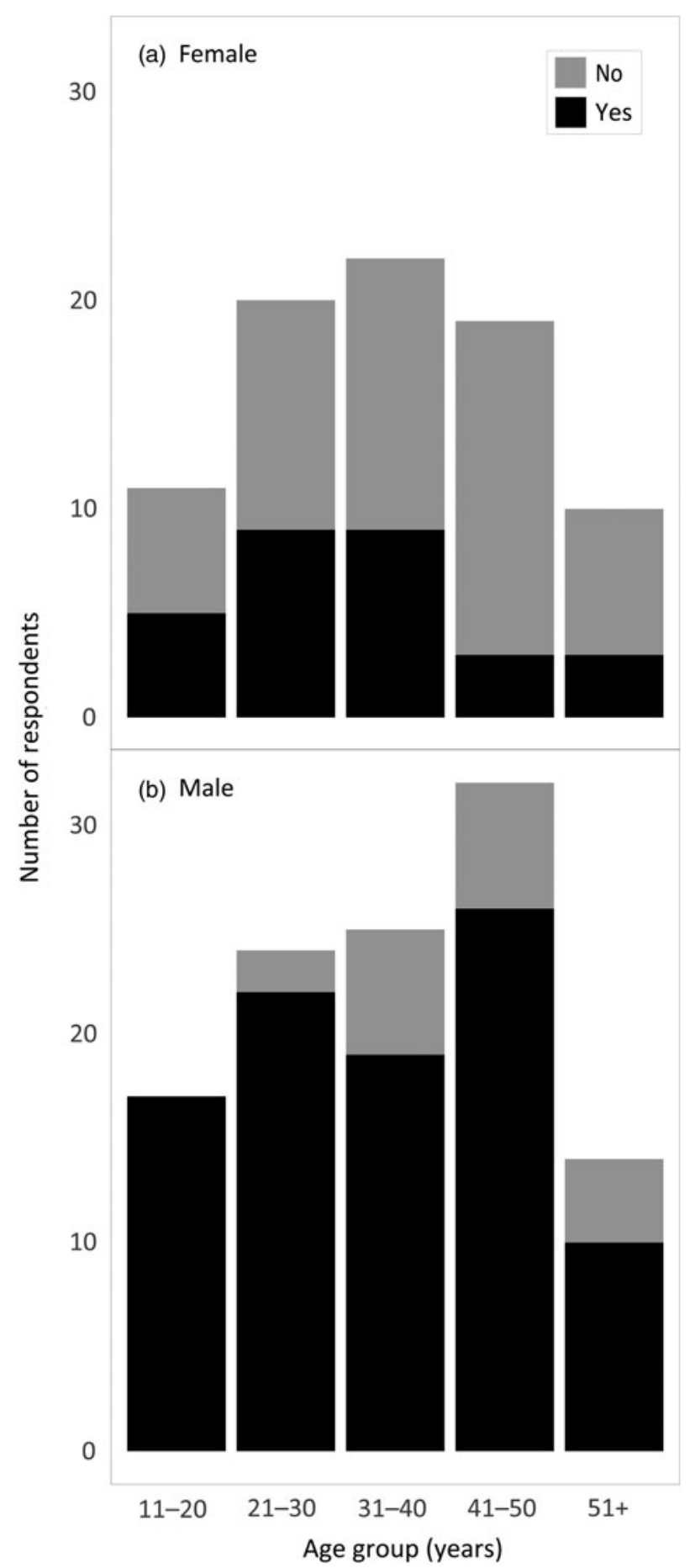

FIG. 2 Reponses of (a) female and (b) male survey participants in five age groups on Makira Island (Fig. 1) to the question 'Do you hunt flying-foxes?'.

A majority of participants (91.9\%) reported that both species of Pteropus were eaten on Makira. The remaining 8.1\% of participants (all from Star Harbour, Rawo and Arosi) stated that $P$. tonganus was the only species hunted for bushmeat. Over $20 \%$ of respondents (9 of 41) from Arosi (the region with the lowest hunting index) stated that only $P$. tonganus was eaten. In response to the question 'The teeth of which flying fox are used for traditional money?' $88.2 \%$ of people reported $P$. tonganus. The remaining $11.8 \%$ indicated the teeth of both P. tonganus and P. cognatus were used.

Responses to the question 'Which flying fox do you see most often?' varied geographically. Regions with the highest hunting pressure indices (Bauro and Star Harbour) reported $P$. cognatus as being the most common species, whereas regions with the lowest hunting pressure indices (Wainoni/ Kahua, Rawo and Arosi) reported P. tonganus as being most common (Fig. 3).

\section{Customary use}

The ranking of various commodities and forms of traditional currency was consistent across age groups (Fig. 4a,b). Overall, participants ranked the values of five commodities to culture and society in the following order: (1) traditional currency and local foods (taro, sweet potato, etc.) (index = 1.54); (2) pigs (index =1.38); (3) Solomon Islands dollars (index =1.17); and (4) store-bought food (index $=0.33$ ). When asked about four forms of traditional currency used on Makira, participants ranked them in the following order of value: (1) shell money (index $=1.31$ ); (2) flying-fox teeth (index $=0.30$ ); (3) dolphin teeth (index $=0.08$ ); and (4) dog teeth (index $=-1.1$ ).

The frequencies with which currencies were used corresponded with values assigned to them by respondents. The most valuable currency (shell money) was also the most commonly used for paying bride price and compensation claims, and for buying local food. Flying-fox teeth and dolphin teeth were the second and third most commonly used currencies, respectively, and dog teeth were the least commonly used (Fig. 5). In semi-structured interviews participants from Star Harbour/Santa Ana advised that dog teeth were once second in value to shell money, but their use has declined.

The best ordinal logistic regression models on Likert data showed age and region were important variables in determining responses to three statements about the use of traditional currencies (Table 2, Fig. 6). Older age groups were more likely than younger people to disagree or strongly disagree that cash was replacing traditional currency, and that there would be no future need for traditional currencies (Fig. 6a,c). A greater proportion of people from Arosi disagreed or strongly disagreed that traditional money was becoming more rare or expensive and that there would be no future need for traditional currencies (Fig. 6b,d). Responses to the three statements, by gender, age group and region, are in Supplementary Table S1.

In semi-structured questionnaires, interviewees stressed the significance of traditional currencies and were concerned 
TABLE 1 Data from five regions of Makira Island (Fig. 1), with the most common Christian sect, population, percentage of survey respondents that hunted, mean number of days spent hunting per year, and percentage of respondents that perceived the Makira flying fox Pteropus cognatus and the Pacific flying fox P. tonganus were in decline.

\begin{tabular}{|c|c|c|c|c|c|c|}
\hline Region & $\begin{array}{l}\text { Most common } \\
\text { Christian sect }\end{array}$ & $\begin{array}{l}\text { Population } \\
(2009)\end{array}$ & $\begin{array}{l}\% \text { of } \\
\text { respondents } \\
\text { that hunt }\end{array}$ & $\begin{array}{l}\text { Mean no. of days } \\
\text { spent hunting } \\
\text { per year }\end{array}$ & $\begin{array}{l}\text { Perceived } \\
\text { P. cognatus } \\
\text { in decline } \\
\text { (\% respondents) }\end{array}$ & $\begin{array}{l}\text { Perceived } \\
\text { P. tonganus } \\
\text { in decline } \\
\text { (\% respondents) }\end{array}$ \\
\hline Bauro & Catholic & 10,112 & 75.0 & $66.1 \pm$ SD 100.3 & 100.0 & 100.0 \\
\hline Star Harbour & Anglican & 6,758 & 64.1 & $61.3 \pm$ SD 119.1 & 85.0 & 90.0 \\
\hline Wainoni/Kahua & $\begin{array}{l}\text { Catholic/South Seas } \\
\text { Evangelical Church }\end{array}$ & 4,619 & 65.0 & $31.9 \pm$ SD 79.0 & 95.0 & 97.5 \\
\hline Rawo & $\begin{array}{l}\text { South Seas Evangelical } \\
\text { Church }\end{array}$ & 4,979 & 58.3 & $15.3 \pm$ SD 17.8 & 97.2 & 100.0 \\
\hline Arosi & Anglican & 9,416 & 53.6 & $5.6 \pm \mathrm{SD} 9.9$ & 12.2 & 21.9 \\
\hline
\end{tabular}

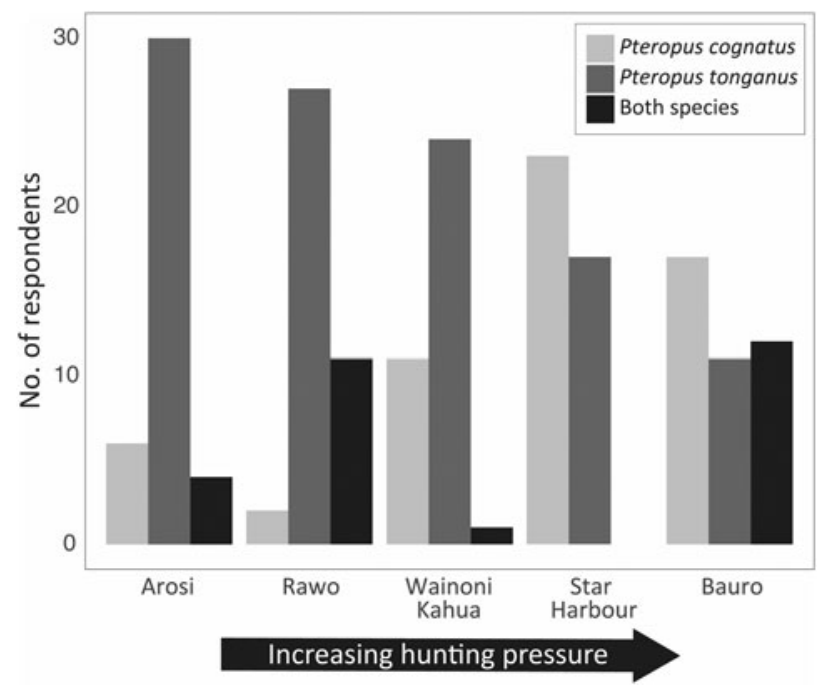

FIG. 3 Responses of survey participants from five regions of Makira Island (Fig. 1) to the question 'Which flying-fox species do you see most often?'. Regions are listed in order of hunting pressure from lowest (Arosi) to highest (Bauro).

about the future of their use on Makira. All respondents made similar statements to the effect that the use of flying-fox teeth is not as significant as it was in the past.

\section{Discussion}

Traditional currencies remain highly valued on Makira, more so than modern currency (Solomon Islands dollars). Among the four forms we investigated, flying-fox teeth were the second most highly valued (after shell money).

Our results suggest the value of flying-fox teeth on Makira may not be an independent driver of hunting but potentially compounds hunting pressure for bushmeat. Only a single interviewee reported hunting flying foxes solely for their teeth. Teeth used as traditional currency are derived almost entirely from $P$. tonganus. Interviewees reported the preference for $P$. tonganus over $P$. cognatus was because the former has larger canines. All Pteropus canines may be used as traditional money but it is more difficult to drill holes in the smaller teeth of $P$. cognatus for necklaces. Both species of Pteropus were commonly eaten, but our data suggest there is preferential targeting of $P$. tonganus. Pteropus tonganus was considered to be increasingly common across the regions as indications of hunting pressure decreased. In Arosi, where hunting pressure is lowest and $P$. tonganus was considered to be most common, $20 \%$ of people reported it was the only species they hunted.

Regional variation in hunting pressure was independent of population size. There was considerable variation in the proportions of people that hunted, and hunting frequency, between Bauro and Arosi, even though both regions have a similar population size. There are a number of external influences not captured by our surveys that may explain why hunting pressure varied between regions. For example, Makira's capital (Kirakira) lies within Bauro, and attracts people from other regions $(>2,000$ people live in Kirakira; Solomon Islands Government, 2009b). In Kirakira cash income is more essential because of reduced access to land for gardening, and increased reliance on store-bought commodities. Bauro was the only region where interviewees reported selling flying foxes for money.

Unsustainable harvesting of $P$. tonganus has led to significant population declines, and extirpations on a number of Pacific Islands (Graham, 1992; Craig et al., 1994a,b; Koopman \& Steadman, 1995; Brooke \& Tschapka, 2002; Mickleburgh et al., 2002; Mildenstein et al., 2016). Residents from regions with the highest hunting pressure agreed almost unanimously that $P$. tonganus populations were declining, and that it was the least common of Makira's two flying-fox species. As a widespread and wideranging species, $P$. tonganus plays a key role in the maintenance of forest ecosystems throughout many parts of the Pacific (Cox et al., 1992; Cox \& Elmqvist, 2000; McConkey et al., 2004; McConkey \& Drake, 2006). As only two 

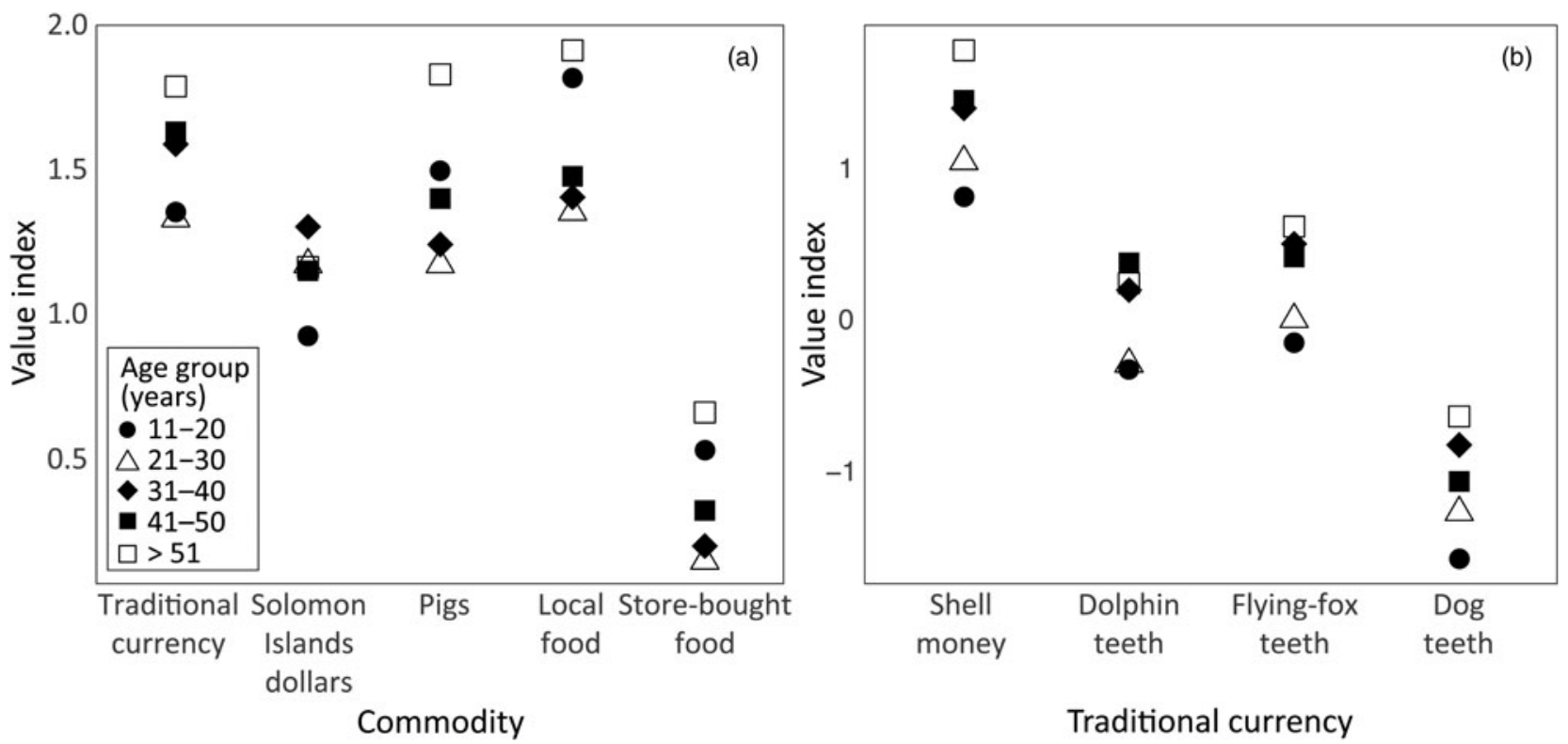

FIG. 4 Values to culture and society of (a) commodities used on Makira Island (Fig. 1) and (b) four forms of traditional currency, assigned by survey respondents in five age groups. Note the different value index scales of (a) and (b).

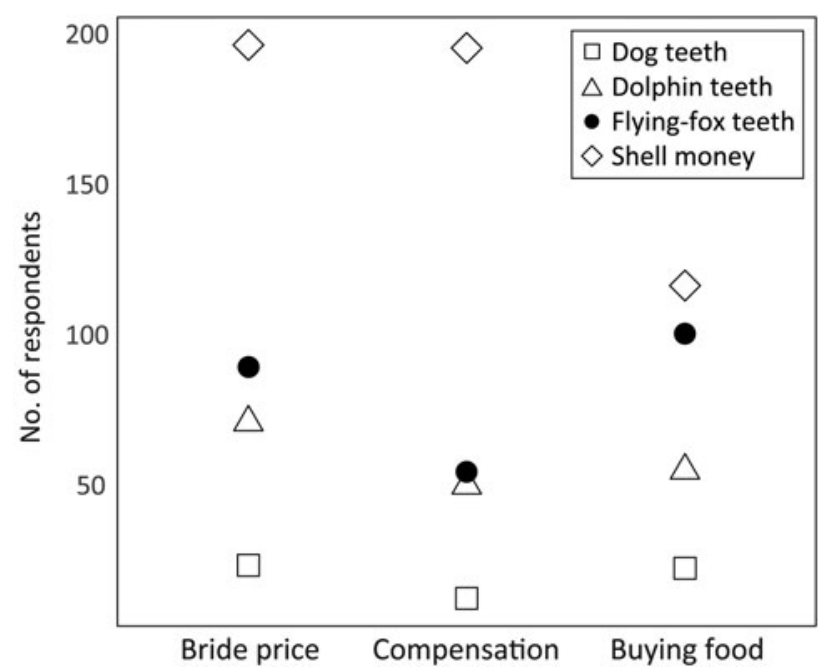

FIG. 5 Responses of survey participants on Makira Island (Fig. 1) to the question 'Which forms of traditional currency are used for paying bride price and compensation, and buying local food?'.

Pteropus species occur on Makira, their ecological importance in terms of pollination and seed dispersal may be proportionately greater than on islands with more diverse assemblages of flying foxes. Furthermore, the role of flying foxes as dispersers can depend on maintaining densities above a certain threshold, and therefore their effectiveness in this ecological function can be greatly reduced by population decreases (McConkey \& Drake, 2006, 2015). Controlling the over-exploitation of flying foxes is therefore an important conservation action for Makira and the wider Solomon Islands (Bowen-Jones et al., 1997).
Geographical variation in hunting pressure across Makira may offer an opportunity for a regional approach to managing this threat. Parts of Makira that already sustain low hunting pressure could provide a useful starting point for establishing conservation refuges; however, it will be important to consider the mobility and ecology of both species. On Makira, flying foxes are commonly hunted using torches and slings when they come to forage in village gardens, rather than by targeting diurnal roosts (JF \& THL, pers. obs.). If either species forages widely across regions, focusing efforts in one area will provide limited benefit.

Our study revealed patterns that warrant further exploration of ecological data. The crucial next step is to quantify flying-fox populations on Makira and determine whether or not current harvest rates are sustainable. Population studies could also extend to the interactions between flying foxes and plants to determine how seed dispersal and pollination services may be affected by hunting.

According to younger Solomon Islanders, cash is replacing the use of flying-fox teeth and there will be no need for traditional currency in the future. This may simply indicate that younger people are less likely to have experienced the need for traditional money (e.g. getting married, contributing bride price for children, and indiscretions that warrant compensation payments). Conversely, older people who are proud of their culture may reject the idea that these practices are being replaced. In semi-structured interviews, people expressed the significance of traditional currency in Makira culture and were apprehensive about its future use.

We recognize the explicit need to ensure the use of flying foxes in Solomon Islands is sustainable, particularly given the increasing human population. However, we do not 
TABLE 2 The best performing ordinal regression models for Likert scale responses to three statements about the value of traditional currencies on Makira, with Cox \& Snell $R^{2}$, Nagelkerke's $R^{2}$, and Akaike's information criterion (AIC) values.

\begin{tabular}{lllll}
\hline Question & Best model & Cox \& Snell $R^{2}$ & Nagelkerke's $R^{2}$ & AIC \\
\hline Solomon dollars are replacing traditional currency. & Age & 0.07 & 0.08 & 396.37 \\
Traditional currency is becoming rare/expensive. & Region & 0.13 & 0.21 & 165.12 \\
There will be no future need for traditional currency. & Age + region & 0.12 & 0.13 & 390.41 \\
\hline
\end{tabular}

\section{$\square$ Strongly agree $\square$ Agree $\square$ Disagree $\square$ Strongly disagree}

(a) Solomon dollars are replacing traditional currency

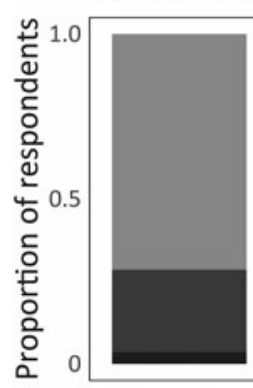

(c) No future need for traditional currency (b) Traditional currency is becoming rare/expensive
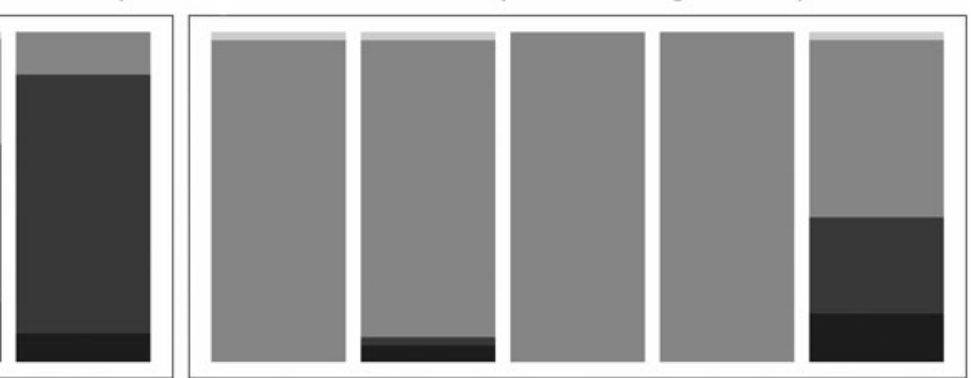

(d) No future need for traditional currency

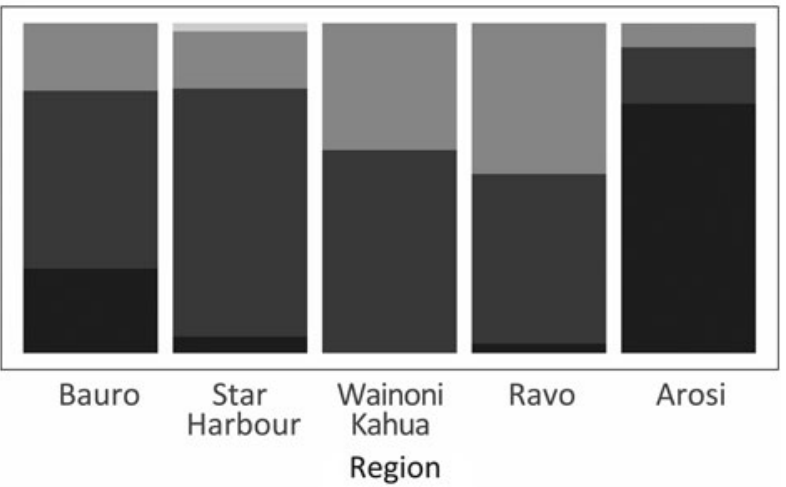

FIG. 6 Responses of survey participants in five age groups (a \& c) and five regions of Makira Island (b \& d) to the statements (a) Solomon dollars are replacing traditional currency to pay bride price and compensation; (b) Traditional currency is becoming more difficult to find or more expensive; and (c) and (d) In the future there will be no need for traditional currency.

necessarily consider the curtailment of the customary use of flying-fox teeth as currency to be a positive option for conservation. Species that provide an important cultural resource can be highly treasured, to the extent that even introduced species can become incorporated into cultural values (see Aslin \& Bennett, 2000 and Robinson \& Whitehead, 2003 for Australian examples). Furthermore, our data indicate that even if the use of flying-fox teeth is declining this does not necessarily translate to a reduction in hunting pressure. Highlighting the cultural value of flying foxes and the threats they face could be a useful starting point for building conservation awareness on Makira.

\section{Acknowledgements}

We thank the communities who participated in questionnaire surveys and offered information about Makira's bats. This work was facilitated by the Critical Ecosystem Partnership Fund to plan for the recovery and long-term conservation of the Makira flying fox. Bruce Patterson and John Terrell provided helpful comments on a draft manuscript and Chris Phillip facilitated access to the anthropological collection at the Field Museum of Natural History, Chicago, USA.

\section{Author contributions}

THL and JF prepared survey questions; JF led the surveys on Makira; and THL analysed the data quantitatively and qualitatively. Both authors wrote the article.

\section{References}

Aкаike, H. (1973) Information theory and an extension of the maximum likelihood principle. In Second International Symposium 
on Information Theory (eds B.N. Petrov \& F. Caski), pp. 267-281. Akademiai Kiado, Budapest, Hungary.

Aslin, H.J. \& Bennett, D.H. (200o) Wildlife and world views: Australian attitudes toward wildlife. Human Dimensions of Wildlife, 5, 15-35.

Boone, JR, H.N. \& Boone, D.A. (2012) Analysing Likert data. Journal of Extension, 50, 2 TOT2.

Bowen-Jones, E., Abrutat, D., Markham, B. \& Bowe, S. (1997) Flying foxes on Choiseul (Solomon Islands) - the need for conservation action. Oryx, 31, 209-217.

BRooke, A.P. \& TsChaPKA, M. (2002) Threats from overhunting to the flying fox, Pteropus tonganus, (Chiroptera: Pteropodidae) on Niue Island, South Pacific Ocean. Biological Conservation, 103, 343-348.

Cameron, R. (2009) A sequential mixed model research design: design, analytical and display issues. International Journal of Multiple Research Approaches, 3, 140-152.

ConnelL, J. (1977) The Bougainville connection: changes in the economic context of shell money production in Malaita. Oceania, 48, 81-101.

Cox, P.A. \& Elmqvist, T. (2000) Pollinator extinction in the Pacific Islands. Conservation Biology, 14, 1237-1239.

Cox, P.A., Elmqvist, T., Pierson, E.D. \& Rainey, W.E. (1992) Flying foxes as pollinators and seed dispersers in Pacific Island ecosystems. In Pacific Island Flying Foxes: Proceedings of an International Conservation Conference (eds D.E. Wilson \& G.L. Graham), pp. 18-23. U.S. Fish and Wildlife Service, Washington, DC, USA.

Craig, P., Morrell, T.E. \& So'oto, K. (1994a) Subsistence harvest of birds, fruit bats, and other game in American Samoa, 1990-1991. Pacific Science, 48, 344-352.

Craig, P., Trail, P. \& Morrell, T.E. (1994b) The decline of fruit bats in American Samoa due to hurricanes and overhunting. Biological Conservation, 69, 261-266.

Creswell, J.W. (2012) Educational Research: Planning, Conducting, and Evaluating Quantitative and Qualitative Research. Pearson, New York, USA.

Fernández-Navarro, F., Riccardi, A. \& Carloni, S. (2015) Ordinal regression by a generalized force-based model. IEEE Transactions on Cybernetics, 45, 844-857.

Flannery, T.F. (1995) Mammals of the South-West Pacific \& Moluccan Islands. Cornell University Press, Ithaca, USA.

Garland, R. (1991) The mid-point on a rating scale: is it desirable? Marketing Bulletin, 2, 66-70.

Graham, G.L. (1992) Conservation and subsistence harvesting of Pacific Island flying foxes. In Pacific Island Flying Foxes: Proceedings of an International Conservation Conference (eds D.E. Wilson \& G.L. Graham), pp. 46-50. U.S. Fish and Wildlife Service, Washington, DC, USA.

Greene, J.C., Caracelli, V.J. \& Graham, W.F. (1989) Toward a conceptual framework for mixed-method evaluation designs. Educational Evaluation and Policy Analysis, 11, 255-274.

Hamilton, S. \& Helgen, K. (2008) Pteropus tonganus. In The IUCN Red List of Threatened Species 2008: e.T18764A8587601. Http://dx. doi.org/10.2305/IUCN.UK.2008.RLTS.T18764A8587601.en [accessed 3 July 2017].

IUCN (2017) The IUCN Red List of Threatened Species 2017-1. Http:// www.iucnredlist.org/ [accessed 29 June 2017].

James, R., Hamilton, S. \& Helgen, K. (2008) Pteropus cognatus. In The IUCN Red List of Threatened Species. Http://dx.doi.org/10.2305/ IUCN.UK.2008.RLTS.T136397A4286239.en. [accessed 7 March 2017].

Jeanty, G.C. \& Hibel, J. (2011) Mixed methods research of adult family care home residents and informal caregivers. The Qualitative Report, 16, 635-656.

Johnson, R.B., Onwuegbuzie, A.J. \& Turner, L.A. (2007) Toward a definition of mixed methods research. Journal of Mixed Methods Research, 1, 112-133.
Jones, K.E., Mickleburgh, S.P., Sechrest, W. \& Walsh, A.L. (2009) Global overview of the conservation of island bats: importance, challenges, and opportunities. In Island Bats: Evolution, Ecology \& Conservation (eds T.H. Fleming \& P.A. Racey), pp. 496530. The University of Chicago Press, Chicago, USA.

Koopman, K.F. \& Steadman, D.W. (1995) Extinction and biogeography of bats on 'Eua, Kingdom of Tonga. American Museum Novitates, 3125, 11-13.

Lavery, T.H., Olds, A.D., Seddon, J.M. \& Leung, L.K.-P. (2016) The mammals of northern Melanesia: speciation, ecology, and biogeography. Mammal Review, 46, 60-76.

MCConkey, K.R. \& Drake, D.R. (2006) Flying foxes cease to function as seed dispersers long before they become rare. Ecology, 87, 271-276.

McConkey, K.R. \& Drake, D.R. (2015) Low redundancy in seed dispersal within an island frugivore community. AoB Plants, 7, http://dx.doi.org/10.1093/aobpla/plvo88.

McConkey, K.R., Drake, D.R., Franklin, J. \& Tonga, F. (2004) Effects of Cyclone Waka on flying foxes (Pteropus tonganus) in the Vava'u Islands of Tonga. Journal of Tropical Ecology, 20, 555-561.

Mickleburgh, S.P., Hutson, A.M. \& Racey, P.A. (2002) A review of the global conservation status of bats. Oryx, 36, 18-34.

Mildenstein, T., Tanshi, I. \& Racey, P.A. (2016) Exploitation of bats for bushmeat and medicine. In Bats in the Anthropocene: Conservation of Bats in a Changing World (eds C.C. Voigt \& T. Kingston), pp. 325-375. Springer Open, London, UK.

Mittermeier, R., Robles Gil, P., Hoffman, M., Pilgrim, J., Brooks, T., Mittermeier, C.G. et al. (2004) Hotspots Revisited. CEMEX, Mexico City, Mexico.

Oremus, M., Leqata, J. \& Baker, C.S. (2015) Resumption of traditional drive hunting of dolphins in the Solomon Islands in 2013. Royal Society Open Science, 2, http://dx.doi.org/10.1098/rsos.140524.

RAMSI (2011) Tok Pijin: A Quick Guide to Speaking Pijin. Regional Assistance Mission to Solomon Islands Public Affairs Unit, Honiara, Solomon Islands.

R Development Core Team (2016) R: A Language and Environment for Statistical Computing. R Foundation for Statistical Computing, Vienna, Austria.

Robinson, C.J. \& Whitehead, P. (2003) Cross-cultural management of pest animal damage: a case study of feral buffalo control in Australia's Kakadu National Park. Environmental Management, 32, 445-458.

Solomon Islands Government (2009a) Report on 2009 Population \& Housing Census: Basic Tables and Census Description, Volume 1. Solomon Islands National Statistics Office, Honiara, Solomon Islands.

Solomon Islands Government (2009b) Provincial Profile of the 2009 Population \& Housing Census: Makira-Ulawa. Solomon Islands Government, Honiara, Solomon Islands.

Stange, K.C., Crabtree, B.F. \& Miller, W.L. (2006) Publishing multimethod research. Annals of Family Medicine, 4, 292-294.

Venables, W.N. \& Ripley, B.D. (2002) Modern Applied Statistics With S. Springer, New York, USA.

Vincenot, C.E., Vincent Florens, F.B. \& Kingston, T. (2017) Can we protect island flying foxes? Science, 355, 1368-1370.

Woodford, C.M. (1908) Notes on the manufacture of the Malaita shell bead money of the Solomon Group. Man, 8, 81-84.

\section{Biographical sketches}

Tyrone Lavery is a Negaunee Interdisciplinary Postdoctoral Fellow at the Field Museum of Natural History, Chicago, USA. His research focuses on Pacific Island biogeography, and taxonomy, conservation and ecology of Melanesian and Australian mammals. JoHn FAsI's research interests include the management of agricultural pests, and the impacts of invasive ants on island ecology. 